\title{
Climate change inferred from borehole temperatures
}

\author{
Henry N. Pollack \\ Department of Geological Sciences, Unicersitv of Michigan, Ann Arbor, Michigan 48109, USA
}

(Recerved January 11, 1992, revised and accepted Apr1l 16, 1992)

\begin{abstract}
Pollack, H N , 1993 Climate change inferred from borehole temperatures Global Planet Change, 7 173-179

Temperature changes at the Earth's surface propagate downward into the subsurface and impart a thermal signature to the rocks that can be analyzed to yield a surface temperature history over the past few centuries Thus subsurface temperatures have the potential to extend the 20th century meteorologic temperature record back well into the pre-1ndustrial era and therefore to provide information relevant to an assessment of the role of greenhouse gases in atmospheric warming Short perıod variations in surface temperature are attenuated at shallow depths, whereas longer period excursions propagate deeper The ability to resolve detals of the surface temperature history dimınishes with tıme Care must be taken to identify and evaluate local anthropogenic temperature perturbations such as urbanization, deforestation and wetland destruction and microclimatic effects associated with topography and vegetation patterns, in order to isolate true regional climate change Investigations in North America indicate significant regional variability in the surface temperature history inferred from borehole profiles, similar to that observed in the meteorologic record of the 20th century.
\end{abstract}

\section{Introduction}

Rock temperatures at shallow depths within the Earth are an archive of temperature changes that have occurred at the surface of the Earth in the recent past Thus subsurface temperatures comprise a valuable complement to surface meteorological data in understandıng the Earth's surface temperature history, particularly for the 19th century and earlier, prior to the establishment of a worldwide network of meteorological stations. Meteorological station records, whıle individually showing considerable variability, have collectıvely shown that the mean temperature of the atmosphere at the Earth's surface has increased by about $0.6^{\circ} \mathrm{C}$ over the past century (Hansen and Lebedeff, 1987). This observed increase of mean atmospheric temperature (Fig 1) is the foundation of the assertion that Earth is experiencing global warming.
Subsurface temperatures offer a widespread and continuous filtered record of surface temperature variations over the past few centuries. In the context of the current discussion over global warming and its likely causes, the time interval represented in the borehole record, comprising both the pre-industrial and industrial eras, is of partıcular sıgnificance and makes the subsurface observations relevant to an assessment of the role of atmospheric greenhouse gases in the warming of the 20th century.

Investigations of ice cores have shown that the concentrations of both $\mathrm{CO}_{2}$ and $\mathrm{CH}_{4}$ in the atmosphere were relatively unchanging until the middle of the 19th century, a time well correlated with the acceleration of the industrial revolution and the increasing combustion of fossil fuels. Then the $\mathrm{CO}_{2}$ and $\mathrm{CH}_{4}$ concentrations began an increase that continues to the present day (Fig. 1). Surprisingly, the history of $\mathrm{CO}_{2}$ and $\mathrm{CH}_{4}$ 


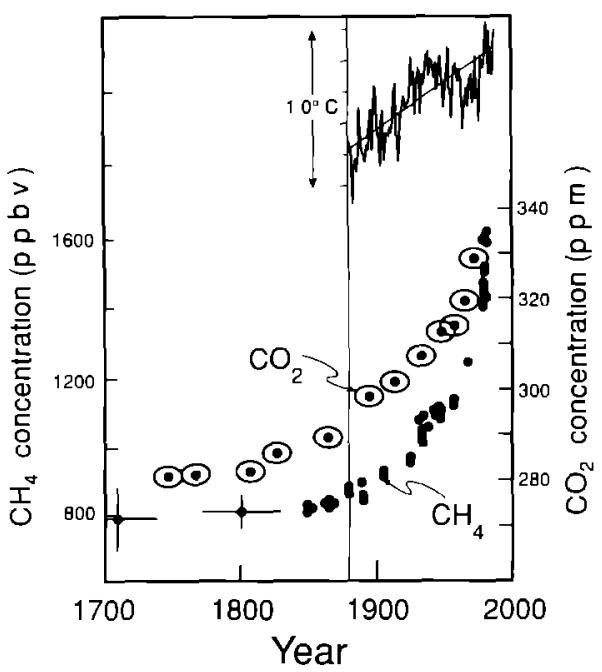

Fig 1 History of surface air temperature change and atmospheric concentrations of carbon dioxide and methane (after Neftel et al , 1985, Pearman and Fraser, 1988, Hansen and Lebedeff, 1987)

concentrations in the atmosphere (Neftel et al., 1985; Pearman et al., 1986) is longer than the meteorological record of surface of temperatures, which on a global basis is only a century long Thus no directly observed surface temperature record exists with which to compare the historical pattern of greenhouse gases concentrations deduced from the pre-industrial era to the present.

The Earth, however, has been mantaining a long archive of surface temperature history in its subsurface, where temperatures have been perturbed by changing conditions at the surface This archive in principle exists everywhere on the continents (the deep ocean floor is shielded from surface temperature fluctuations) and can be accessed by drillıng a borehole and lowering a thermometer to obtain a profile of temperature versus depth In many boreholes, however, the linear increase of temperature with depth that characterızes the geothermal gradient is observed only in the deeper parts of the borehole, shallow temperatures show departures from linearity that indicate other influences on the near-surface heat transfer process, including such possibilities as ground-water movement, topography, vegetation patterns and a changing temperature at the surface.

\section{Surface and subsurface temperatures}

The most obvious temperature oscillations at the Earth's surface are the diurnal and seasonal changes, periodic disturbances with daily and annual periods, respectively. The theory of heat conduction shows that the surface oscillations diffuse downward as a thermal wave, the amplitude of whıch dimınishes exponentially with depth (Fig. 2). Moreover, shorter period oscillations attenuate more rapidly with depth than do longer periods and the process effectively acts as a selective filter, allowing only longer term variations to penetrate to greater depths The daly temperature oscillation penetrates only $1 \mathrm{~m}$ and the seasonal oscillation to about $15 \mathrm{~m}$ before the signal is lost Longer-term oscillations penetrate more deeply, a century long cycle can be observed to $150 \mathrm{~m}$ depth and a millennial period to $500 \mathrm{~m}$. Thus at increasing depths the Earth selectively records longer term trends and excludes short period excursions from the archive, an ideal property for a clımate change recorder (Fig. 3)

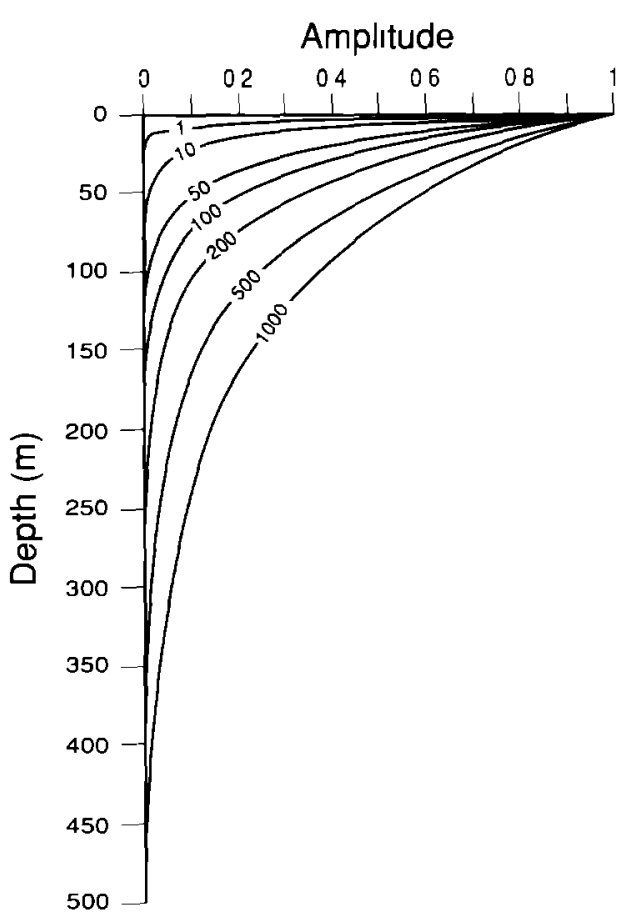

Fig 2 Attenuation of unit amplitude thermal wave with depth in a medium with thermal diffusivity of $10^{-6} \mathrm{~m}^{2} \mathrm{~s}^{-1}$. Numbers on curves are the period of the thermal wave in years 
The solıd Earth is also a good recorder because of the slow pace at which thermal signals diffuse into the subsurface. In general all changes in surface temperature that have occurred in the last millennium are imprinted in the uppermost $500 \mathrm{~m}$ of the Earth's crust, a depth easily attainable by inexpensive drılling The apparent velocity at which a thermal wave travels downward from the surface depends on the period of the oscillation, with the longer periods penetratıng more slowly. For periods of interest, in the range of decades to millennia, the apparent velocity ranges over an order of magnitude from about 5 to $0.5 \mathrm{~m}$ per year A century long oscillation

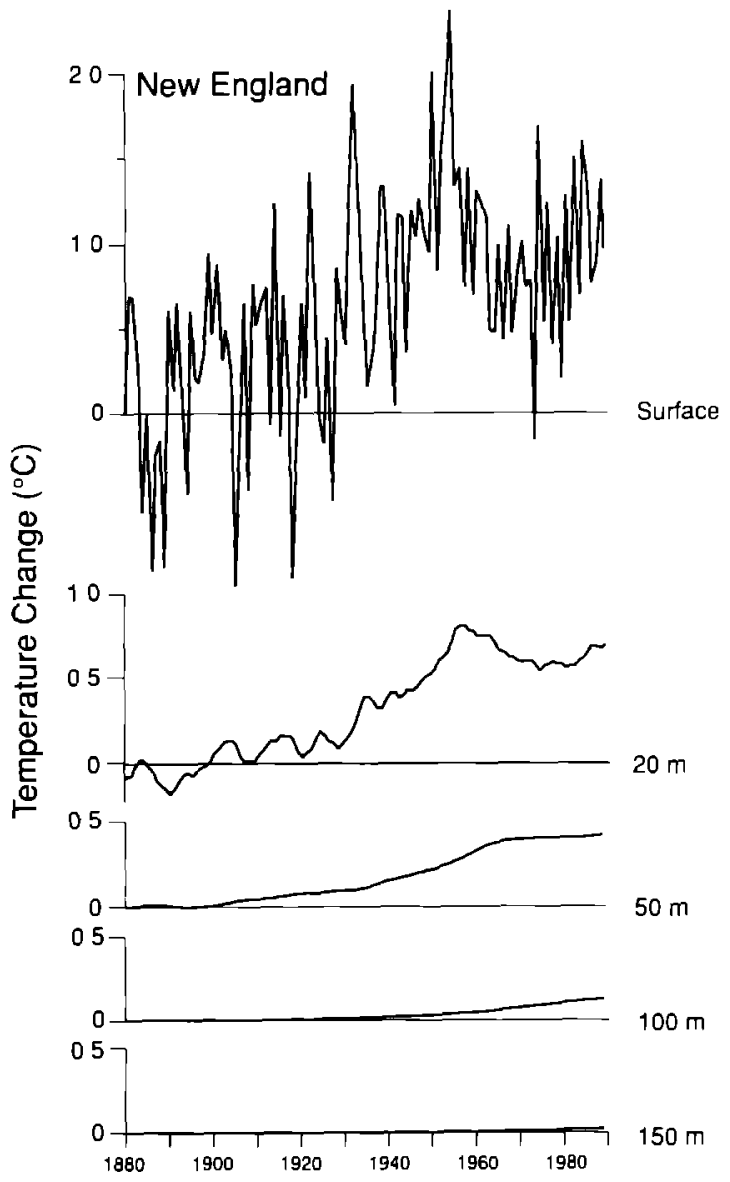

Fig 3 Qbserved surface alr temperature history for northeastern USA since 1880, and calculated temperature histories at different depths Calculations assume a uniform surface temperature prior to 1880 The detalls of the surface history are increasingly filtered out at depth The increase in surface temperature over the 110-yr interval begins to appear at 150 m depth only around 1970.

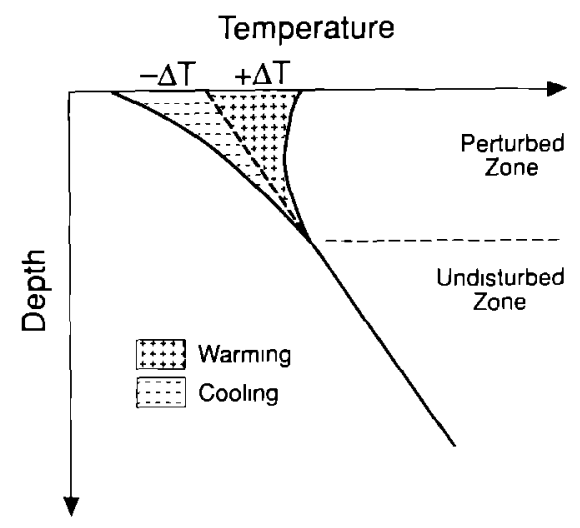

Fig 4 Schematic illustration of subsurface temperature perturbation due to either warming or cooling by an amount DT at the surface The unperturbed linear increase of temperature with depth is the geothermal gradient

begun in 1900 would just be reachıng $150 \mathrm{~m}$ depth today; over the next century, no matter what might be happening at the surface, the temperature at $150 \mathrm{~m}$ depth would be showing a muted and filtered representation of the 20th century and earlier surface temperature history. Thus subsurface temperature fluctuations lag surface temperature variations in time

What are the characteristics of a borehole temperature profile that allow the reconstruction of a surface temperature history? First, the borehole must display at some depth a uniform conductive heat flux from greater depths Because the heat flux is the product of the geothermal gradient and the thermal conductivity of the rock, a determination of the thermal transport properties of the rock is also required. In a homogeneous material the condition of uniform heat flux is equivalent to a constant geothermal gradient, 1.e a linear increase of temperature with depth (Fig. 4) The upward extrapolation of this linear part of the temperature profile reconstructs temperatures that existed at shallower depths prior to the onset of a surface temperature excursion The difference between the surface intercept of the extrapolated geothermal gradient and the present-day ground surface temperature indicates the present-day magnitude of the temperature excursion A second characteristic is the depth at which the curved portion of the profile departs from the undisturbed geothermal gradient; this 
depth is a function of the time of onset of the temperature excursion. Third, the variable curvature in the temperature profile in the perturbed zone above the undisturbed geothermal gradient provides detail about the changes in the surface temperature through time which have led to the present-day value Both forward and inverse modellıng techniques have been developed to analyze temperature profiles (B1rch, 1948; Beck and Judge, 1969; Cermak, 1971; Beck, 1982; Shen and Beck, 1983, 1991; Vasseur et al., 1983; Lachenbruch and Marshall, 1986; Mareschal and Beltrami, 1992; Wang, 1992). The inversions generally show that the resolved surface temperature at a time in the past is roughly the average temperature experienced in a time window of duration similar to the interval of time that has elapsed between the earlier tıme and the present day (Fig. 5). Thus the resolved temperature at the surface ten years ago would be roughly the mean temperature the surface experienced between five and fifteen years ago Further back in time, e.g. 200 years ago, the resolved temperature at the surface would be the average temperature experienced between 100 and 300 years ago. Clearly the ability to resolve details of the surface temperature history diminishes with time

\section{Synthetic Temperature History}

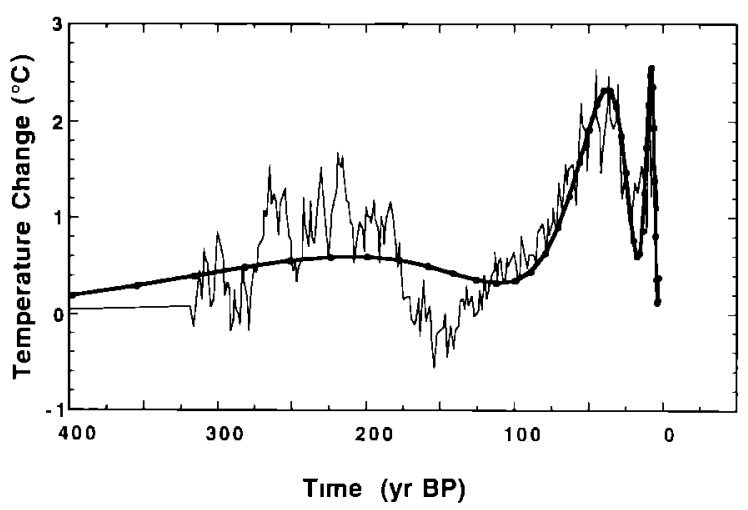

Fig 5 Surface temperature history (bold line) derived by inversion of subsurface response to three century long Arctic surface temperature record (fine line) inferred from tree-ring analyses (Jacoby and D'Arrigo, 1989), showing resolution achievable from subsurface temperatures (after Chapman and Clow, 1991)

\section{Problems}

In practice, the extraction of local histories from subsurface temperatures is strewn with pitfalls, because there are many processes and situations that lead to borehole temperature profiles simular to those expected from a variation of surface temperature over tıme Several fall into the category of anthropogenic microclimatic change and include the effects of deforestation and agricultural expansion each of which leads to a warming of the Earth's surface by direct exposure to solar radiation. Wetland destruction eliminates the cooling effect of evaporation and is followed by a surface warmıng. Urbanization also leads to a warming through increased absorption of solar radiation by roads and structures and the interior heating of buildings. The onset of each of the environmental modifications is closely associated with increased human activity and therefore has a time scale not unlike that associated with anthropogenic modifications of the atmosphere through increased production of $\mathrm{CO}_{2}$ and $\mathrm{CH}_{4}$.

Aspects of the local topography, hydrology and vegetative patterns can also lead to thermal perturbations in the subsurface that can be mistaken for regional clımate change. Topographic relief is typically accompanied by an increase of the geothermal gradient beneath valleys and a decrease beneath hills; both effects dimınish with depth below the irregular surface, but in the shallow subsurface produce temperature distortıons that mımıc a changing surface temperature. Some lakes do not completely freeze throughout their depth even though seasonal temperatures fall well below freezing over adjacent land. Such "warm bottom" lakes distort the subsurface temperatures nearby and could lead to a misinterpretation in terms of a changing climate Ground water movements and non-uniform rock properties can also affect subsurface temperatures and leave a signature that in some circumstances looks remarkably like a response to surface temperature change. Fortunately, most of these geologic thermal disturbances can be quantitatively modeled and theır magnitudes estımated. Another approach with certain advantages focuses on regional ensembles of borehole logs, to see if bore- 
holes spread across hundreds of kılometers of continental terrain have common perturbations in their temperature profiles. As it is highly unlikely that all of the boreholes would have identical topography, vegetation, geological structure, or hydrologic settings and disturbances, a common temperature perturbation can more safely be ascribed to climate change.

\section{Preliminary results}

Already several geothermal data sets from North America have been analyzed for evidence of surface temperature changes Investigations in the Alaskan arctic (Lachenbruch et al., 1982; Lachenbruch and Marshall, 1986) have provided evidence of significant warming in the northern high latitudes Temperature profiles from a number of wells spread across $500 \mathrm{~km}$ of northern Alaska have anomalous curvature in the upper $100-150 \mathrm{~m}$ of the wells (Fig. 6). The curvature is consistent with a warming at the top of the permafrost of some $2-4^{\circ} \mathrm{C}$, the duration of the warming event varies for different sites, but at nearly all sites it has a 20th century onset. The magnitude of the surface warming inferred from the Alaskan boreholes is substantially greater than global average warming of the 20th century, but is consistent with the few polar meteorologic records.
An equally clear but lower amplitude warming is documented in temperature profiles from boreholes in eastern and central Canada. Independent studies (Cermak, 1971, Sass et al., 1971; Nielsen and Beck, 1988; Beltramı and Mareschal, 1991, Mareschal and Beltrami, 1991; Wang, 1992) show warming of $1-2^{\circ} \mathrm{C}$ in the last $100-200$ years. The 20 th century warming appears to be in part a recovery from an earlier one or two-century cooling trend that bottomed out in the 1800's The sites are spread across Ontario and Quebec and, as is the case in the Alaskan arctic, the warming is variable between sites in both magnitude and tımıng and occasionally absent.

Anomalous curvature is also found in temperatures profiles from boreholes in the North American Great Plains (Gosnold and Bauer, 1990), from which a temperature increase of about $2^{\circ} \mathrm{C}$ in North Dakota and Wyoming has been inferred. Data from southern South Dakota and Nebraska, on the other hand, indicate little change over the past 100 years And in the desert of western Utah, borehole temperature profiles suggest only a small amount of warming in this century, averaging $0.3^{\circ} \mathrm{C}$ at six sites and local cooling at one site (Chisholm and Chapman, 1992).

These preliminary results indicate that the broad outlines of the regional and temporal varlation of the Earth's surface temperature over the past few centuries is recoverable from the subsur-

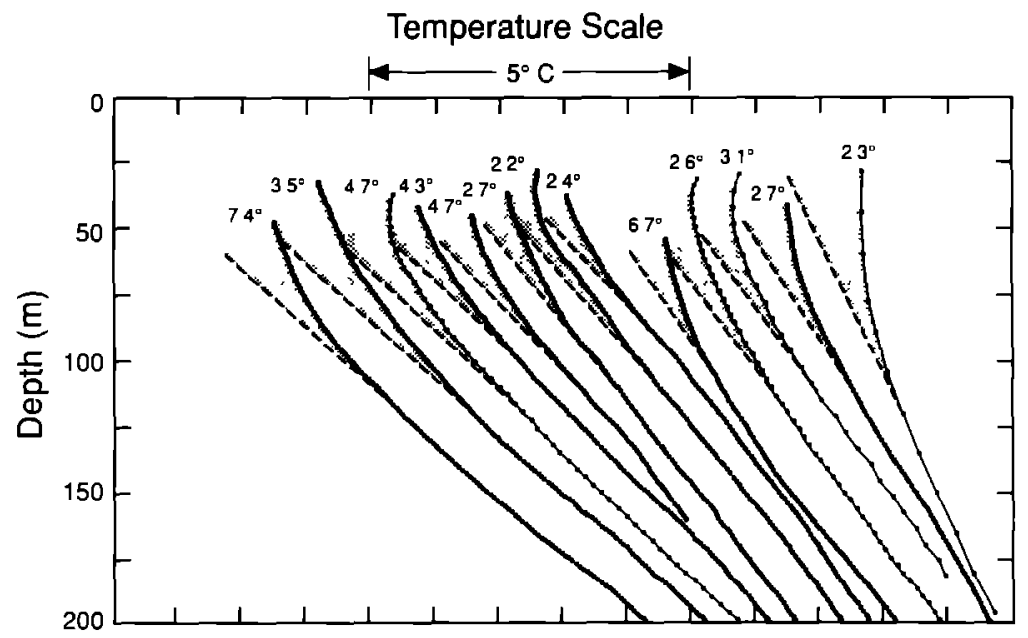

Fig 6 Borehole temperature observations from arctic Alaska (Lachenbruch and Marshall, 1986) The temperature profiles are offset to avoid overlap. The number above each profile indicates the magnitude of the local warming and the shaded region for each curve represents the warmıng anomaly 
face thermal record. What is the potential for these studies to be extended to other areas, to provide the geographic coverage necessary to delineate global trends over the past few centuries? As noted earlier, the subsurface temperature archive is confined to the continents where the Earth's solid surface is exposed to the atmosphere. Geophysicists have for three decades been systematically taking the Earth's temperature at many continental locations as part of an effort to map the heat loss from the Earth's interior (Pollack et al, 1990). Thus a considerable body of subsurface temperature observations already exIsts, some of which have sufficient depth extent, resolution and ancillary information available to enable the reconstruction of the surface temperature history At the 1991 meetıng of the Internatıonal Heat Flow Commission, a group comprising geothermal researchers organızed under the auspices of the International Association of Seısmology and Physics of the Earth's Interior, a new workıng group was established to collect these existıng data and develop a unifıed data base of subsurface temperatures and other relevant information to serve as the observational foundation for a worldwide analysis of historical temperature trends.

The Earth, while richly and widely endowed with subsurface temperature information, will not yield a global history easily. One important reason is that a global history must be developed as a weighted integration of many local histories. As the meteorological records have shown, there is significant regional variability in the 20th century history of atmospheric temperatures some areas show warmıng that exceeds the global average, some show warmıng that falls short of the global mean and some even show cooling The significant point is that no single area yields a signal that represents the global average; a global history comprises a wide range of local histories and is derived from them.

Reconstructıng the recent history of the Earth's climate, however, will ultimately require more than just a knowledge of the surface temperature history, because climate is the complex composite of temperature, precipitation, wind, cloud cover and other factors. Information about these sev- eral factors can be gleaned from many sources, including tree rings, coral growth patterns, ice cores, lake and ocean sediments and historical commercial and agricultural records. Studies in all these areas are revealing that changes in the Earth's clımate take place on many different tıme scales and with considerable regional variability. The integration of these diverse regional observatıons has the promise of yieldıng a coherent global picture

\section{Acknowledgments}

This paper is an adaptation of an article submitted to Scientific Amerıcan (Pollack and Chapman, 1993) The preparation of both papers has been supported in part by the US National Sclence Foundation, Grants EAR-9104292 and ATM-9121450.

\section{References}

Beck, A E, 1982 Precision logging of temperature gradients and the extraction of past climate, Tectonophysics, 83 $1-11$

Beck, A E and Judge, A, 1969 Analysis of heat flow data I Detaled observations in a single borehole Geophys J R. Astron Soc , 18 145-158.

Beltramı, H and J-C, 1991 Mareschal, Recent warmıng in eastern Canada inferred from geothermal measurements Geophys Res Lett, 18 605-608

Birch, F, 1948 The effects of Pleistocene climatic varıations on geothermal gradients Am J. Scl, 246 729-760

Cermak, V, 1971 Underground temperature and inferred climatic temperature of the past millenium Palaeogeogr, Palaeoclımatol., Palaeoecol, 10 1-19

Chapman, D S and Clow, G D., 1991 Surface temperature histories reconstructed from borehole temperatures a geothermal contribution to the study of climate change EOS Trans Am Geophys Unın, 72 (suppl), p 69 (abstract)

Chısholm, T J and Chapman, D S, 1992 Climatıc changes inferred from analysis of borehole temperatures an example from western Utah J Geophys Res, 97 14,15514.176

Gosnold, W D and Bauer, M, 1990. The climate record in borehole temperatures in the north central United States EOS Trans Am Geophys Unıon, 71, p 1597 (abstract)

Hansen, J and Lebedeff, S, 1987 Global trends of measured surface alr temperature J Geophys Res, 92 13,34513,372

Jacoby Jr , G C and D'Arrıgo, R, 1989 Reconstructed northern hemisphere annual temperature since 1671 based on high-latıtude tree-ring data from North America Clim Change, $14 \quad 39-59$ 
Lachenbruch, A and Marshall, B V , 1986 Changing clımate geothermal evidence from permafrost in the Alaskan arctıc Science, 234, 689-696

Lachenbruch, A H, Sass, J H, Marshall, B V and Moses Jr, T H, 1982 Permafrost, heat flow, and the geothermal regime at Prudhoe Bay, Alaska, J Geophys Res, 879301-9316

Lewis, T J, 1975 A geothermal survey at Lake Dufault, Quebec Thesis. Univ West Ont, London

Mareschal, J C and Beltramı, H, 1992 Evidence for recent warmıng from perturbed geothermal gradients examples from eastern Canada Clım Dyn., 6 135-143

Neftel, A, Moor, E, Oeschger, H and Stauffer, B, 1985 Evidence from polar ice cores for the increase in atmospheric $\mathrm{CO}_{2}$ in the past two centuries, Nature, 315 45-47

Nielsen, S B and Beck, A, 1988 Heat flow density values and paleoclımate determıned from stochasic inversion of four temperature-depth profiles from the Superior province of the Canadian shield Tectonophysics, 164 345-359

\section{Note added in proof}

A special issue of this journal (vol 6, issue 2-4, December 1992, edited by T Lewis) contains 18 research papers addressing aspects of climate change inferred from underground temperatures
Pearman, G I. and Fraser, P J, 1988 Sources of increased methane Nature, $332 \quad 489-490$

Pearman, G I, Etheridge, D, de Sılva, F and Fraser, P J , 1986 Evidence of changıng concentrations of atmospheric $\mathrm{CO}_{2}, \mathrm{~N}_{2} \mathrm{O}$ and $\mathrm{CH}_{4}$ from air bubbles in Antarctic ice Nature, $320248-250$

Pollack, H N . Hurter, S J and Johnson, J R, 1990 The new global heat flow data complation EOS Trans Am. Geophys Unıon, 71, p 1604 (abstract)

Pollack, HN and Chapman, D S, 1993 Earth's changıng climate a history read from subsurface temperatures Sci. Am , 286, in press

Sass, J H, Lachenbruch. A H and Jessop, A M, 1971 UnIform heat flow in a deep hole in the Canadian Shield and its paleoclimatic implications J Geophys Res, 76 85868596

Shen, PY and Beck, AE, 1991 Least squares inversion of borehole temperature medsurements in functional space J Geophys Res, 96 19,965-19.979

Shen, P Y and Beck, A E, 1983 Determination of surface temperature history from borehole temperature gradients J Geophys Res, 88 7485-7493

Vasseur, G, Bernard, P H, Van de Meulebrouck, J, Kast, Y and Jolivet, J., 1983. Holocene palaeotemperatures deduced from geothermal measurements Palaeogeogr, Paldeoclimatol., Palaeoecol, 43 237-259

Wang, K, 1992 Estımation of ground surface temperatures from borehole temperature data J Geophys Res, 97 $2095-2106$ 